\title{
Research on the Teaching of College Comprehensive English Based on Production-oriented Approach
}

\author{
Hongping Chen \\ School of Foreign Languages, North China Electric Power University, Baoding, 071000, China \\ Yu Zhang* \\ School of Foreign Languages, North China Electric Power University, Baoding, 071000, China
}

\begin{abstract}
Production-oriented approach (POA) is a kind of teaching theory aiming at overcoming the disadvantages of "separation of learning and application" in foreign language teaching in China. With Chinese characteristics, it is suitable for middle and senior foreign language learners. In order to improve the teaching effect of current College English Comprehensive English, this paper will proceed from the current situation of College English teaching, based on the teaching concept of POA, explore the applicability of POA in College English comprehensive classroom, and carry out the teaching design from the three stages of pre-class, while class and after class. In addition, this paper puts forward targeted teaching suggestions for the teaching of College Comprehensive English course, in order to take the classroom as a practical process of cultural and language socialization, truly implement the concept of humanistic quality education, and cultivate a number of foreign language talents needed by the society.
\end{abstract}

Keywords: Production-oriented approach; College comprehensive english teaching; Student; Teacher.

(9) (1) CC BY: Creative Commons Attribution License 4.0

\section{Introduction}

Ministry of Education issued the College English Teaching Guide, it pointed out: the current College English teaching goal is to cultivate the students' English application ability, strengthen the consciousness of cross-cultural communication and interpersonal skills, improve the comprehensive cultural literacy, so that they can effectively use English in their study, life, social communication and future work, and meet the needs of national, social, school and personal development.

Since the promulgation of the guide, College English teaching is facing unprecedented pressure of reform, especially in the application-oriented undergraduate schools. At the same time, with the rapid development of global information technology, China has entered the era of "high-speed development of Internet", and education has also entered the era of "high-speed development of Internet" education. In this context, the traditional College English teaching model has seriously affected the cultivation of students' core qualities. In addition, under the background of "One Belt And One Road" initiative, the cooperation and exchanges between China and other countries are unprecedentedly frequent. China is in urgent need of a large number of comprehensive compound talents with both professional ability and communicative ability in foreign languages.

However, college English in most colleges and universities in China is faced with a sharp decrease in class hours. Under the circumstance of compressed class hours, many teachers are tired of completing the teaching schedule and give students little productive language training in class. For a long time, the traditional teaching mode of college English class in China has emphasized input rather than output, and it is dominated by the teaching of language knowledge points, namely knowledge input. As a result, students' subjective initiative is low, which leads to weak motivation, low interest in learning, time consuming and low efficiency, and low participation in class, greatly reducing the teaching effect.

POA is a set of teaching theoretical methods based on the output driven hypothesis ("output-driven"-"inputenabled") and explored by Professor Wen Qiufang and her team of Beijing Foreign Studies University. Under the strong call for reform and the recommendation of professor Wen Qiufang in the domestic and international teaching seminars, this teaching method has attracted the attention of foreign language experts and teachers, and some teachers began to try to use it in the classroom. In terms of the number of journal articles included by CNKI, as of May 31, 2018, there were 21 papers on this teaching theory, while only 9 papers on teaching practice and application. For example, Wenjuan Zhang designed a teaching process based on the "POA" (Zhang and Wenjuan, 2016); Qizhang Gu believes that the use of "POA" teaching strategy in English class can improve students' critical thinking ability and classroom efficiency Gu Qizhang (2016). The classroom, as a practice process of socialization of culture and language, can effectively carry out humanistic quality education. At the same time, POA also has a certain influence in the international academic circle. POA builders were invited to make keynote speeches at several international conferences. In 2016, Qiufang Wen published the paper "the production-oriented approach to teaching university students English in China" in the international journal language teaching (Wen, 2016). Wong \& Hyland published Faces of English Education in 2017, and in chapter seven of this book wrote "The production-oriented 
approach: A pedagogical innovation in university English teaching in China" (Wen, 2017) .It can be seen that although domestic scholars have conducted extensive studies with the "production-oriented approach", the research contents are scattered and no complete system has been formed. Moreover, most of the research methods are speculative, with few empirical studies and even fewer action studies based on specific classroom teaching problems, therefore, this thesis is based on the theory of POA, aiming at the existing problems in College English teaching, and carrying out action research on College English teaching, to improve the comprehensive ability of college students and promoting their all-round development.

\section{Introduction to the Theory of POA}

POA is a set of teaching theories developed by professor wen Qiufang of Beijing foreign language university and her team on the basis of output driven hypothesis (output-driven-input-enabled). POA divides teaching into three parts: Teaching Theory ("learning-centered", "learning-using integrated" and "whole-person education"), teaching hypothesis ("output-driven", "input-enabled" and "selective learning") and teaching process (motivating,enabling and assessing). The three parts are interrelated and mutually supported. The teaching concept is the basis of teaching hypothesis and teaching process design; the teaching hypothesis is the basis of teaching. Teaching hypothesis provides a strong theoretical guidance for the design of teaching process; teaching hypothesis and teaching concepts are integrated into and run through all aspects of the teaching process, and teachers play an important intermediary role in all aspects of the teaching process. POA subverts the traditional teaching mode of "input first, then output". Its teaching process is "drive to promote evaluate", which enables students to learn independently under the "output drive". The teaching concept of POA include "learning-centered", "learning-using integrated" and "whole-person education". Different from the form student-centered, POA advocates that teaching must achieve teaching objectives and promote effective learning. This can better reflect the essence of school education.

\section{Feasibility Analysis and Promotion Approaches}

POA is an attempt to construct a foreign language teaching theory with Chinese characteristics, which is quite in line with college English teaching requirements. POA aims to achieve humanity through the following three means:

First, choose the topic of the output task carefully. POA believes that topics conducive to the realization of humanistic goals can be divided into two categories: 1) helping students to establish a correct world view, outlook on life and values; 2) it is conducive to cultivating students' ability of communication and mutual learning between Chinese culture and foreign civilizations and spreading Chinese culture. In other words, one kind of topic is about how to promote the healthy growth of students, the other is about how to make students shoulder the social responsibility of promoting cultural exchanges between China and foreign countries.

Second, carefully select the input materials for output tasks. On the one hand, teachers select language materials with high ideological level and positive energy to cultivate students' sentiment and help to establish a correct ideological value system; on the other hand, teachers select language materials reflecting social and political hot topics at home and abroad to cultivate students' the sense of homeland and broaden students' International vision.

Third, skillfully design the organizational form of teaching activities. For example, teachers can cultivate students' spirit of mutual assistance and cooperation through group activities, and also improve students' ability to objectively evaluate others' advantages and disadvantages through students' mutual evaluation of output results.

\section{Research Design \\ 4.1. Research Object}

The research object of this project is the first year freshmen of class 2019 of North China Electric Power University, who are taught by the members of the research group. There are about 15 classes, and the number of students in each class is about 60-70. Since 2017, the College English of North China Electric Power University has carried out the curriculum reform, the course name has been changed to comprehensive English, and the way of natural class teaching is adopted. There are great differences in the English level of students from different majors. Therefore, the experimental group and the control group are only divided in the same major, and there will be no significant difference in English proficiency between the two groups.

\subsection{Research Objectives to Be Achieved}

This paper, taking the comprehensive English reading and writing teaching as an example, advocates the implementation of "integration of speaking, reading, writing and translation", that is, under the guidance of POA, based on the rules of language acquisition, guided by students' learning requirements and future career needs, designs oral, writing and translation tasks, and drives the learning desire for the input of text knowledge points and other contents. Then after students discuss and teachers' guidance, promote the task of output again, Teachers make evaluation again according to the output display so as to consolidate the internalized input knowledge and form a virtuous circle.

\subsection{The Key Problem to Be Solved}

In order to comply with the situation and requirements of the National College English teaching reform, our university has reduced College English credits since September 2017, teaching reading and writing separately from 
listening and speaking, and students' listening in the computer room adopt the form of self-study. But the teaching method of reading and writing has not changed obviously. English teaching still adopts the "text centered approach", that is, "warming up before class - text learning - practice after class" teaching mode, with the goal of understanding words, sentences and texts. But the teaching method of reading and writing has not changed obviously. English teaching still adopts the "text centered approach", that is, "warming up before class - text learning - practice after class" teaching mode, with the goal of understanding words, sentences and texts.

\subsection{Course Design}

The teaching practice part of this study is composed of three stages: before class, during class and after class. It gives full play to the guarantee function of multiple evaluation incentive mechanism combining formative evaluation and summative evaluation, and is implemented in two environments: campus network teaching platform and classroom.

First of all, before class, teachers should make clear the teaching objectives of the course, and then determine the settings and types of output tasks (oral tasks with real scenes, theme writing or practical writing related to future career needs, or paragraph translations, etc.), set two or three output tasks with different degrees of difficulty for students of different levels. Secondly, the teacher selects the input materials based on the principle of promoting the output task, and uploads the related theme videos, PPT of new words and phrases in textbooks and other auxiliary learning materials one week in advance by using the online teaching platform, so that students can carry out personalized learning before class; the teacher selects the input materials based on the principle of promoting the output task, and uploads the related theme videos, PPT of new words and phrases in textbooks and other auxiliary learning materials one week in advance by using the online teaching platform, so that students can carry out personalized learning before class; At the same time, teachers assign tasks to inform students how to use these materials and set pre-class independent learning tests to guide students to pay more attention to certain key information. Finally, the teacher develops a new multi evaluation incentive mechanism to encourage students to study carefully before class, and discusses the difficult problems encountered in autonomous learning, or upload their own practice works for students and teachers to make joint comments, and the teacher gives corresponding guidance and summarizes the problems in students' autonomous learning, so as to prepare for classroom teaching and interaction.

Second, in the face-to-face classroom teaching, teachers first check the students' autonomous learning in different forms, such as quiz, competition and so on. Then, explain the key points of the lesson and the difficult problems existing in the students, and conduct interactive questions and answers with the students. Then, the teacher divides the work into groups according to the output task before class. In the process of group negotiation and discussion, the teacher instructed or led the excellent students to select useful input materials and expressions for the students to further practice the output. Finally, each group shows the results, and teachers make accurate and meaningful evaluation and feedback, so that students can really benefit from it. At the same time, in the presentation of each group, other students are required to observe and study carefully, and then summarize the main points of the presentation of the group, make oral evaluation and score. Then, the teacher summarizes and supplements the information and practices that the reporter should learn and share, so that all students can learn something.

Third, homework and evaluation. After class, it is the stage of consolidating and improving knowledge and skills. According to the unit teaching goal, the teacher arranges the after class consolidation exercises of language knowledge points, as well as some review output tasks and transfer tasks, so as to expand and sublimate the students' output ability.

In order to ensure the smooth development of this teaching reform, we changed the previous assessment method which focused on the summative assessment but despised the process assessment. At the beginning of the experiment, we established a compound evaluation incentive mechanism with students and teachers to participate in the scoring, and included online homework, online test, online discussion, classroom quiz, classroom performance, and the homework all into the category of formative assessment, the score of classroom performance increased to $40 \%$, and the final evaluation accounted for $60 \%$. In this process, the teacher establishes learning files for each student and announces them regularly, so as to encourage the students to take the initiative in learning. It can be seen that the scaffolding role of teachers is indispensable in all stages of class.

\section{Practical Suggestions on Teaching Design of POA}

Based on the POA, College English teaching puts forward high requirements for teachers, which requires teachers as the leader to fully prepare before class and grasp the overall situation of teaching materials, courses and students. The design of the task is the key and the difficulty of the whole process. Teachers must understand the needs of students and the society, and at the same time, the task should be interesting to a certain extent, to create a "real" situation in class so that students have enough enthusiasm to invest time and energy to complete a large number of tasks outside class. In addition, students' language skills and negative emotions should be taken into account, as these will affect the final effect.

Teachers' guidance can effectively help students to complete their tasks. Teachers' participation in the tasks of each group is the guarantee of students' high quality completion. Students are the main body of learning. Unlike the traditional intensive reading teaching method, now students need to complete tasks independently according to the materials provided by teachers. If they can't solve problems in the classroom, they need to make use of library, network and other resources to solve problems by themselves. Teachers' guidance reduces students' anxiety and 
pressure. At the same time, teachers still need to solve the specific operation problems of more groups and less class hours.

The rational division of labor of the group can allow members to participate actively. In fact, because of the different levels and degrees of participation in some groups, some members have little participation. How to group, how to make members cooperate with each other, and how to let high-level members guide low-level members are worthy of teachers' consideration and further exploration.

The rational division of labor of the group can allow members to participate actively. It is different matter to set a good evaluation standard and to evaluate according to the standard. Evaluation can sometimes be mixed with subjective factors, some high-quality works will be given lower scores by some groups because of personal emotions or other problems. Students participate in the assessment process, which is also a process of peer learning. In this aspect, teachers will continue to mobilize the enthusiasm and participation of students and fairness.

\section{Conclusion}

In order to establish an effective classroom teaching mechanism, front-line teachers must play an active role. In this teaching practice, we apply POA to the teaching of reading and writing. The teaching goal is clear, and leads and mobilizes enthusiasm of students' learning, and finally successfully completes the teaching task. Due to various subjective and objective reasons, our teaching design is not mature enough, and many details of classroom teaching need to be improved. Due to the short time of the experiment, there may be many difficulties and problems that have not been exposed. It is expected that more and more excellent English teachers will make more classroom attempts, enrich and improve the teaching design of the POA, and that this theory will bring fruitful teaching results to foreign language teaching in China.

\section{References}

$\mathrm{Gu}$ Qizhang (2016). Output oriented approach, and the improvement of the efficiency of humanistic quality education in english classroom. The journal of Education Review, (06): 139-41.

Wen, Q. F. (2016). The production oriented approach to teaching university students English in China. Language Teaching, 51(4): 526-40.

Wen, Q. F. (2017). "The production-oriented approach: A pedagogical innovation in university English teaching in China." In L. Wong \& K. Hyland (eds.). Faces of English: Students, Teachers, and Pedagogy . London and New York: Routledge. pp. 91-106.

Zhang Wenjuan (2016). College English classroom teaching experiment based on output oriented approach. The Journal of Foreign Language and Foreign Language Teaching, (2): 106-14. 